\title{
THE RELATIONSHIP BETWEEN LEADERSHIP STYLES AND AVIATION SAFETY: A STUDY OF AVIATION INDUSTRY
}

\author{
Dipak Prasad Bastola \\ Kathmandu University School of Management, Nepal
}

\begin{abstract}
The role of leadership in aviation safety is the subject of great interest. Aviation safety is related foremost to passenger safety, and ultimately to the economy. A single aviation accident can lead to organizational failures due to financial burden and loss of life. Therefore, the role of aviation leader in safety issues needs to be examined. In this article, 300 aviators, both managers and employees, have participated in the survey which utilized the Multifactor Leadership Questionnaire (MLQ), and the Nordic Network of Occupational Safety Questionnaire (NOSACQ50). Three separate organizations were chosen for the study. A quantitative research methodology was used to analyse the research findings. The research results show that the safety level of most of the airlines under the investigation was below the desired level. Likewise, transformational leadership has a higher safety score than any other leadership styles; however, only a few aviation leaders are practising this style. It implies that aviation leaders can adopt a transformational style to reduce air accidents. This research also identified a few core competencies of the aviation leader within the transformational style of leadership. Intellectual stimulation and individualized consideration can contribute to higher aviation safety than any other factors of transformational leadership.
\end{abstract}

KEYWORDS: Aviation safety, Leadership, Leadership style, Transformational leadership, Transactional leadership and Non-Transactional leadership (Laissez-faire leadership) style. 


\section{INTRODUCTION}

A high-risk industry like aviation is exposed to risk every day, and thus its workers too are exposed to aviation risks right from starting their job. Moreover, safety is costly, and it is hard to achieve it without all employees and leadership's contribution. Flin (1998) suggested that safety can be monitored before failure. He emphasized the feedback of employees to achieve safety.

Nepal is one of the unsafe skies as per the recent International Civil Aviation Organization (ICAO) result. European Aviation Safety Agency (EASA) has already blacklisted Nepal for its poor safety record. No Nepali aircraft is allowed to enter the European airspace due to its weak safety measures and the fact of having been blacklisted. Nepali aviation history shows that, so far, more than 60 air mishaps have occurred within 60 years of its history of aviation operation in Nepal (Civil Aviation Authority of Nepal [CAAN], 2020). Due to having been blacklisted by EASA, the Nepali airline industry is facing severe financial and other problems.

The Nepali aviation industry is always in a shadow in terms of its research and development. The government has never prioritized research-based policy. However, a few safety-related studies were found in the literature. A large-scale cross-sectional study of Danish companies by Andersen and his fellow researchers (Bass, 1985) was one of them. They suggested that planning and management strategies are required to increase the safety level. Therefore, I have carried out empirical research in the aviation field, which could be useful to all the aviation industries worldwide. An aviation accident or incident has severe impacts on the aviation industry. For instance, the case of Boeing Max accident had severe adverse effects on the aviation industry (ICAO, 2020).

To culminate this type of air accident, the ICAO has recently formulated the safety management system. As per this, training, technology, and regulations are the three primary safety defense layers (ICAO, 2020). Air accidents' main problems are organizational politics, unfortunate management, less safety culture, lack of training, and political instability in the country (ACSNI, 1993). Moreover, safety climate and attitude are the evaluation measures of organizational safety (Diaz \& Cabrera, 1996). In 2015, Alam conducted a study and highlighted that aviation accident happens due to not focusing on safety culture and safety climate at the workplace of the aviation industry (Alam, 2015). Most air accidents occur due to the airlines' poor leadership and safety culture (Barrick \& Mount, 1991). 
So far, in Nepal, more workplace incidents have happened in the aviation industry (CAAN, 2020). In the year 2019, the Nepali civil aviation minister died, and the author had participated as one of the experts in the aircraft crash investigation commission. The final investigation report highlighted a severe flaw in operational management, and they have a low safety climate at their organization. The commission recommended improving the entire Nepali aviation industry's safety climate, which can minimize such types of air accidents (CAAN, 2020).

Recent Studies and research findings have concluded that corrupt management practices and leadership styles are potentially dangerous for aviation safety (ICAO, 2020). All the research in the field of leadership and safety were related to general organizations. So far, no such study has been carried out in the area of the aviation industry. Moreover, not many studies were explicitly related to leadership and aviation safety (Cox \& Cox, 1991). The recent aviation accident report has also pointed out the management failure to prevent air accidents in most aviation accidents (Reason et al., 1998).

The research article is separated into several sections. The introductory section defines the research problem, offers the author's motivation to the research issue, and introduces the case company. The relevant literature review is carried out in the literature review section. The analysis provides the conditions that guide the investigation of the relationship between leadership styles and the workplace's safety climate. The methods section talks about the research approach, i.e., quantitative research approach, sampling and data collection, and data analysis procedure. In the conclusion section, based on the study's significant findings, implications and conclusions are drawn.

Moreover, the scientific contribution of this study is highlighted under a separate sub-heading. Limitations of the research are also identified, and further research on the relationship between leadership styles and safety climate in the aviation industry other than Nepal has been recommended. This type of research finding can be used around the globe to enhance aviation safety, which can save many lives. This research could be the first such kind of research in the field of leadership style and aviation safety. It can increase the safety level of the aviation organization, which, in turn, minimizes air accidents in the future. 


\section{LITERATURE REVIEW}

All different researchers have defined leadership as per their perspective and knowledge. Leadership should be trustworthy, needs to motivate followers, and always lead the followers to achieve the organizational goal (Yukl, 2010). Due to a lack of motivation, employees slowly deviate from their safety culture, and there will be a low safety climate. Some of the crucial factors for several major accidents that happened in the 20th century were low safety culture, failure of leadership, and managerial failure at the organizational level (Hofmann \& Stetzer, 1996).

One of the accidents that illustrate this fact was the crash of DC. 10 KZ-NZP. Flight 901 in Mount Erebus, Antarctica from Auckland Airport New Zealand on 28 November 1979. In this accident, 237 passengers and 20 crew onboard had died. The cause was that they had changed the flight path of the aircraft $45 \mathrm{KM}$ to the East early in the morning, but the management did not inform them about the change (ICAO, 2020).

As per the recent accident investigation report of one of the helicopters crashed in the eastern part of Nepal, it was pointed out that lack of safety climate at that airline's workplace was the contributory factor of air accident that occurred (CAAN, 2020). Leaders are responsible for creating a suitable safety climate in their aviation organization (Patankar \& Sabin, 2010). All different kinds of employees have different attitudes and behaviours, resulting in an aviation safety climate (Kelly et al., 2015). Safety climate, and safety culture, could be bettered by executing programs that focus on co-worker trust, supervisor trust, and job satisfaction (Simard \& Marchand, 1994). Safety beliefs depend on and lead to safety culture, and, in Nepal, we also have a distinctive culture, that is, luck culture (Bastola, 2017). When there is an accident or incident, we blame it mostly on bad luck.

According to Kelly (2012), there are many differences and commonalities in leadership styles and safety culture, especially safety climate. He found that there was a positive relationship between transformational leadership with safety climate. Another researcher, Brin (2010), pointed out that transformational leadership is considered one of the best leadership styles to achieve higher organizational performance. Likewise, Bass (1985) also agree that better performing leaders have a transformational leadership style. A transformational leader always helps their employees to reach their career goals and incur better output. However, transactional leadership always prioritizes the specific transaction among the followers and leaders (Bass, 1985). 
As per Chena (2013), both leadership style and safety climate can be measured by one item and one scale as aviation safety starts from the hanger or where the maintenance people work. As per Wameedh et al. (2011), occupational accidents are rising due to a lack of attention given to safety act, safety actions, and improvement of methods to prevent accidents and injuries. Andoh (2013) further describes transactional leadership and indicates that it is based on social learning and social exchange theories. He concluded that the transactional leadership style has less performance than the transformational leadership style.

Safety climate directly influences employees' safety motivation and knowledge, which directly affects safety performance activities, which is also directly related to safety outcomes (Smith et al., 1978). The fact is that many small airlines think first about profit than safety. Aviation leaders are not like general leadership; they need to decide on time due to the higher mobility of aviation industries (Williamson et al., 1997). Aviation safety tell-tale indicators are lagging or leading indicators, which depend on the safety climate. Safety climate should be like affair climate (O'Connor, 2011). Likewise, leadership styles are mainly affected by organizational culture, national culture, followers, situations, organizational structural (Fuller, 1999).

There are some studies in the field of safety culture and safety climate of an organization, mainly in general organizations like nuclear processing plant (Lee, 1998). He concluded that leadership role in the safety culture of the plant is vital and cannot be neglected. Another research in the field has been carried out in road transportation administration and found that leaders can build the workplace's safety culture than any other employees (Niskanen, 1994). Aviation organizations have different employees, where crew, other employees and their various backgrounds and safety culture indirectly affect safety. Furthermore, leadership style can help to manage safety. As such, the safety level is the result of an organizational safety climate and leadership style. How the leadership style contributes to safety and which leadership is the best for achieving a higher level of safety climate has been studied in this research.

From the above literature, we assume that leadership styles directly influence safety culture and safety climate. The performance of the organization also depends on a positive safety climate. However, so far, no single research is available in the field of leadership and aviation organizational safety climate as per the author's knowledge. In this context, many questions remained unanswered: Why is air accident increasing trend? Which leadership style could be the best for a better safety climate in the aviation industry? Out of these queries, the author 
personally has chosen the topic "The relationship between leadership styles and aviation safety climate- a study of Nepali airlines" as empirical research to fulfil the research gaps and to contribute knowledge in the field of leadership and aviation safety.

Based on the above literature, we could not identify any clear-cut relationship between the leadership style of a leader of an aviation organization and the safety climate. Therefore, the link can be organized according to concepts derived from the purpose and research problem and from aviation-related safety studies published in journal articles, dissertations, and meta-analyses, as presented in the research study's theoretical framework. Leadership styles can affect various safety factors, as shown in Figure 1 below. In this research, the author is interested in the effect of leadership styles on aviation safety climate.

The theoretical framework is based on two variables, leadership styles and safety climate. Leadership styles are independent variables, and safety climate is the dependent variable. As mentioned above, to what extent leadership styles and safety climate are related, there is no clear-cut evidence from the literature. Therefore, this research aims to study the relationship between leadership style and the safety climate at Nepali airline industries to recommend the best leadership practices for aviation leadership. More specifically, this research study has the following research questions:

- To what extent does an organization's leadership styles (transactional, transformational, or non-transactional) correlate with aviation safety climates in aviation industries?

- Which leadership style correlates with a higher safety climate?

- Which individual factors of leadership styles are highly correlated with aviation safety climate?

This study is based on empirical research, which was carried out by using a survey questionnaire to the top managers and working-class employees. Based on the above research questions, this research tried to find out the relationship between leadership style and aviation safety climate in three different types of aviation organizations, government, semi-government and private aviation organizations, mainly airlines industries. 
Figure 1. Theoretical framework of leadership styles and aviation safety climate

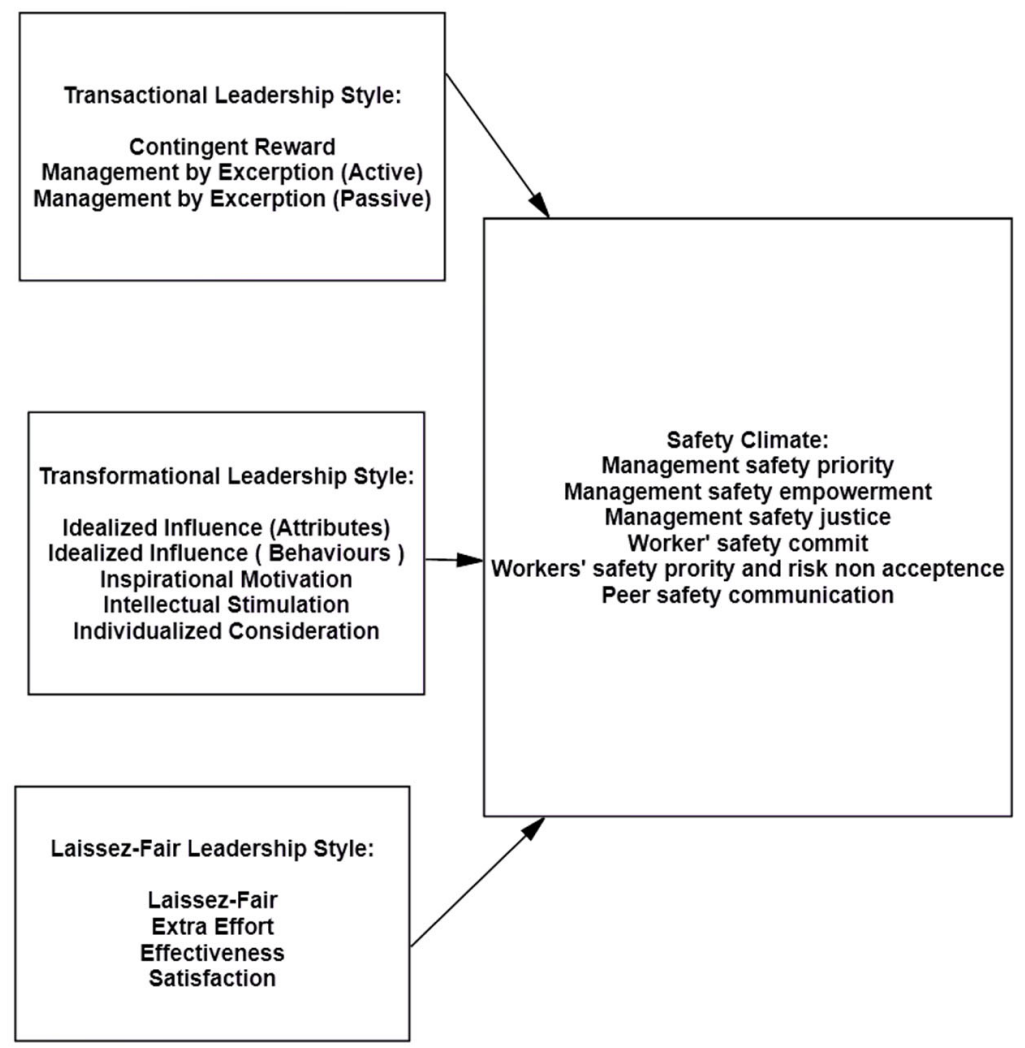

\section{METHODS}

The author himself carried out a pilot survey for this research in 2016. Only 51 people participated, and the result shows the significance of this research, but there were some data collection errors due to language problems. Therefore, the questionnaire had to be translated into the Nepali language. The author was keen to do such research in a larger scale to generalize the result; this was the reason the author has surveyed converting all MLQ and NOSACQ-50 questionnaires into the Nepali language, some items were slightly modified without changing the original themes. Then the author administered the survey in 10 different aviation organizations from 17 December 2019 to 8 January 2020 in Nepal.

The participants for this study had comprised about 300 respondents from various employees of Nepali airlines which are operating in domestic and international track and who agree to respond to a written questionnaire. Sample of employees had been chosen as per convenience for the study at the workplace and few designated leaders as per their appointments. The survey 
participants had comprised a sample of convenience from the staff of airlines, mainly crew pilots, aeronautical engineers, aircraft mechanics, and ground support staff.

The benchmarks for presence in the study had comprised a sample of different age, sex, caste/society, educational background, rank, profession, position, and length of service, etc. Ten various aviation organizations were chosen randomly, one from a government aviation organization, another was a semi-government aviation organization, and seven were private aviation organizations. The rationale for selecting these varied types of organizations is that leadership styles and the safety climate within their organizations could be different in these three types of industries.

This is a quantitative study, and the author has used the primary data collected via a survey. Different models have been used to explore the answers to the research questions. The result is to develop a practical model that will sum up the whole idea of this research. Two survey questionnaires were used for gathering evidence during the study. The first questionnaire, which was used to classify the leadership styles, was the Multifactor Leadership Questionnaire (MLQ) developed by Bass and Avolio (1997). The second questionnaire used to measure the safety climate resulted from a questionnaire developed by the Nordic Network of Occupational Safety Researchers (NOSACQ-50). It was developed based on organizational and safety climate theory, psychological theory, headed by the National Research Centre for the Working Environment, Denmark (Kines et al., 2011).

The NOSACQ-50 questionnaire was given to both the supervisors and the subordinates to fill up. The MLQ measures the attributes of transformational, transactional, and laissez-faire leadership styles with a magnitude scale of $0,1,2,3$, and 4 . The scales are represented by 0 for not at all, 1 for once in a while, 2 for sometimes, 3 for fairly often, and 4 for frequently. For transformational leadership, the scales of 20 questions on idealized attributes, idealized behaviours, inspirational motivation, intellectual stimulation, and individual consideration were used. The scales for transactional leadership comprised contingent reward and management by exception active and are captured by 12 questions. Laissez-faire leadership is characterized by laissez-faire, extra effort, effectiveness, and satisfaction, identified by 13 items. Refer to the Annex for the full survey questioners. After the collection of data, in the first stage, the data had been decoded. There are 12 independent variables (construct) for leadership styles listed with their codes (Leader 1 to Leader 12) for data analysis. 
Leadership Style Transformational:

- Idealized Influence (Attributes) (Leader1)

- Idealized Influence (Behaviors) (Leader2)

- Inspirational Motivation (Leader3)

- Intellectual Stimulation (Leader4)

- Individualized Consideration (Leader5)

Transactional Leadership styles:

- Contingent Reward (Leader6)

- Management by Exception (Active) (Leader7)

- Management by Exception (Passive) (Leader8)

Non-Transactional Leadership Styles:

- Laissez-Faire (Leader9)

\section{Extra Effort (Leader10)}

Effectiveness (Leader 11)

Satisfaction (Leader12)

Likewise, the NOSACQ-50 is made up of 50 questions requiring answers that are ratings $1,2,3$, and 4 , but the rating is dependent on the formulation of the questions. It covers seven safety dimensions, namely: Management safety priority and ability, Management safety empowerment, Management safety justice, Worker's safety commitment, Workers safety priority, and risk nonacceptance, Safety communication, learning, and trust in safety ability, and Workers' trust in the efficacy of safety systems. Both leadership and safety climate survey questioners are tabulated in the Annex.

The MLQ was used to determine and measure leadership styles, whereas the NOSACQ-50 were used to measure workers' perception of the value management places on safety. The NOSACQ50 covers seven dimensions of safety climate (Safety) with its codes (Safety1 to Safety7) for data analysis purpose, namely are as below: 
- Management safety priority and ability (Safety1)

- Management safety empowerment (Safety2)

- Management safety justice (Safety3)

- Worker's safety commitment (Safety4)

- Workers safety priority and risk non-acceptance (Safety5)

- Safety communication, learning, and trust in safety ability (Safety6)

- Workers' trust in the efficacy of safety systems. (Safety7)

To determine the results from the NOSACQ-50, a true mean score has been determined for each dimension for each respondent. After that, the mean for all the respondents was determined from the true means from each respondent. To determine if the leadership style is associated with the safety climate score, the scoring is grouped into three ranges with the following categories: 15 to 19 - low safety, 20 to 24 - medium safety, 25 to 28 - high safety.

The NOSACQ-50 used in this study has been pilot tested in various industries in all the Nordic countries, and the results confirmed the reliability and validity of the questionnaire (Kines et al., 2011). Bass and Avolio (1997) tested the MLQ and found that its reliability is proven many times through test-retest, internal consistency methods, and alternative methods. However, the author is using it in the aviation field for the first time. Therefore, a separate reliability test of each has been carried out and tabulated in the annex table 3 and table 4, respectively. Using SPSS, correlation analysis has determined the relationship between leadership style and the aviation safety climate. The dependent variable is the safety climate, and others are independent or explanatory variables.

Recent research has stressed the potential problem of common method bias, which describes the measurement error compounded by respondents' sociability who want to provide positive answers (Yang et al., 2010). As per Chang et al., it may occur if the same questionnaire is used for two different research constructs. But in this article, the author has used two different independent sets of questionnaires for safety and leadership issues, and data analysis shows the high reliability of the questionnaires. The Variance Inflation Factor (VIF) is less than two (see Table 1), and thus, it is reliable. Latent modelling of variables has been done in the questionnaire itself so that respondents will not understand the survey's full scope, which can reduce the bias. Besides, the author also knew the real data only after the decoding of the questionnaires. 
Table 1. Variance Inflation Factor

\begin{tabular}{|l|c|c|}
\hline Variable & VIF & $1 /$ VIF \\
\hline Extra Effort & 3.05 & 0.32 \\
\hline Effectiveness & 2.83 & 0.35 \\
\hline Contingent Reward & 2.11 & 0.47 \\
\hline Satisfaction & 2.05 & 0.48 \\
\hline Laissez-Faire & 2.00 & 0.49 \\
\hline Management by Exception (Passive) & 1.93 & 0.51 \\
\hline Management by Exception (Active) & 1.85 & 0.54 \\
\hline Idealized Influence (Attributes) & 1.54 & 0.64 \\
\hline Inspirational Motivation & 1.41 & 0.70 \\
\hline Idealized Influence (Behaviours) & 1.37 & 0.72 \\
\hline Intellectual Stimulation & 1.37 & 0.72 \\
\hline Individualized Consideration & 1.28 & 0.77 \\
\hline Mean VIF & 1.9 & \\
\hline
\end{tabular}

Table 2. Cronbach's alpha of Leadership each Construct Variables

\begin{tabular}{|l|l|c|}
\hline & Leadership Factors & $\begin{array}{c}\text { Cronbach's } \\
\text { alpha }\end{array}$ \\
\hline 1 & Idealized Influence (Attributes) (Leader1) & 0.71 \\
\hline 2 & Idealized Influence (Behaviours) (Leader2) & 0.59 \\
\hline 3 & Inspirational Motivation (Leader3) & 0.64 \\
\hline 4 & Intellectual Stimulation (Leader4) & 0.65 \\
\hline 5 & Individualized Consideration (Leader5) & 0.58 \\
\hline 6 & Contingent Reward (Leader6) & 0.76 \\
\hline 7 & Management by Exception (Active) (Leader7) & 0.82 \\
\hline 8 & Management by Exception (Passive) (Leader8) & 0.86 \\
\hline 9 & Laissez-Faire (Leader9) & 0.86 \\
\hline 10 & Extra Effort (Leader10) & 0.90 \\
\hline 11 & Effectiveness (Leader11) & 0.85 \\
\hline 12 & Satisfaction (Leader12) & 0.85 \\
\hline
\end{tabular}

Note: Total Cronbach's alpha of all 45 questions is 0.76. 
The author tried to minimize the common method bias during the survey, but there may be a common method bias (VIF $=1.9$ ), which is the limitation of this article. However, this 1.9 value of VIF is acceptable in the research study since it is less than 2.

Table 3. Cronbach's alpha of Safety Climate Dimensions each Construct Variables

\begin{tabular}{llc}
\hline & Leadership Factors & Cronbach's alpha \\
\hline 1 & Management safety priority and ability (Safety1) & 0.81 \\
2 & Management safety empowerment (Safety2) & 0.51 \\
3 & Management safety justice (Safety3) & 0.82 \\
4 & Worker's safety commitment (Safety4) & 0.64 \\
5 & Workers safety priority and risk non-acceptance (Safety5) & 0.81 \\
6 & Safety communication, learning, and trust in safety ability (Safety6) & 0.70 \\
7 & Workers' trust in the efficacy of safety systems. (Safety7) & 0.55 \\
\hline
\end{tabular}

Note: Total Cronbach's alpha of all 50 questions is 0.935. Cronbach's alpha (Internal consistency) interpretation: a $\geq$ 0.9 (Excellent), $0.9>a \geq 0.8$ (Good), $0.8>a \geq 0.7$ (Acceptable), $0.7>a \geq 0.6$ (Questionable), $0.6>a \geq 0.5$ (Poor), $0.5<\mathrm{a}$ (Unacceptable)

Although all safety and leadership styles, construct variables are very difficult to measure, these above values of Cronbach alpha can be taken as satisfactory for such a complex study with seven dependent construct variables of safety and twelve independent construct variables.

The author did not replicate the survey, which was already done in another place. This is the concept developed by the author to use these above mentioned two questionnaires in the aviation industry in Nepal, and its findings can be generalized around the globe. Both statistical tools SPSS and STATA were used to analyze the data. Since there are seven safety dependent construct variables and 12 independent leadership construct variables, there are high possibilities of the interdependence of such latent variables. Therefore, the author did additional structural equation modelling to show the dependence of dependent and independent variables.

\section{RESULTS}

From the analysis of the data collected at Tribhuvan international airport, it was found that 300 respondents with a $92 \%$ response rate have returned the questionnaire. Altogether 325 people were selected from various airlines and aviation organizations. Due to the limited number of aviators, 325 sample were included in the study, and they were mainly the 
Manager/supervisor/subordinates who were conveniently selected for the study. Twenty-five respondents could not submit the form due to their hectic schedules in their respective organizations. The remaining 300 respondents fruitfully completed and submitted the forms. The socio-demographic profile of the respondents has listed in Table 4.

The results were determined by averaging the scores for each item in each leadership style scale. A leadership style, which has a higher score, indicates a strong tendency toward that leadership style. The various results of this research are tabulated in Table 5. The aviation staffs' numbers were high in the survey respondents. Female respondents were very few; this may be due to very few female aviators working in the Nepali aviation industry. In terms of the Questionnaires' responses, $205(68 \%)$ of the subordinates were male and $95(32 \%)$ female. The respondents were selected based on their work experience, especially those working under a supervisor for more than ten years. Table 5 has shown the result of the regression analysis between leadership styles and safety climate by using STATA.

Table 4. Socio-demographic characteristics of the respondents

\begin{tabular}{llcc}
\hline Variables & Level & Frequency & Rate (\%) \\
\hline Gender & Male & 205 & 68.3 \\
& Female & 95 & 31.7 \\
Age & 19 to 35 & 152 & 50.7 \\
& 36 to 57 & 148 & 49.3 \\
Level of Education & Bachelor or Above & 127 & 42.3 \\
& Intermediate or Plus 2 & 173 & 57.7 \\
Institute & Government & 81 & 27 \\
& Semi- government & 128 & 43 \\
Position or Status & Private & 91 & 30 \\
& Manager or Supervisor & 127 & 42.3
\end{tabular}


Table 5. Correlation matrix between various factors of leadership styles

\begin{tabular}{|c|c|c|c|c|c|c|c|c|c|c|c|c|}
\hline & leader1 & leader2 & leader3 & leader4 & leader5 & leader6 & leader7 & leader8 & leader9 & leader10 & leader11 & leader 12 \\
\hline leader1 & 1 & & & & & & & & & & & \\
\hline leader2 & 0.22 & 1 & & & & & & & & & & \\
\hline leader3 & 0.27 & 0.26 & 1 & & & & & & & & & \\
\hline leader4 & 0.26 & 0.21 & 0.14 & 1 & & & & & & & & \\
\hline leader5 & 0.33 & 0.23 & 0.19 & 0.27 & 1 & & & & & & & \\
\hline leader6 & 0.36 & 0.42 & 0.33 & 0.31 & 0.29 & 1 & & & & & & \\
\hline leader7 & 0.33 & 0.29 & 0.24 & 0.34 & 0.25 & 0.49 & 1 & & & & & \\
\hline leader8 & -0.33 & -0.23 & -0.32 & -0.35 & -0.31 & -0.52 & -0.18 & 1 & & & & \\
\hline leader9 & -0.45 & 0.03 & -0.34 & -0.31 & -0.29 & -0.15 & -0.18 & 0.44 & 1 & & & \\
\hline leader10 & 0.39 & 0.16 & 0.39 & 0.28 & 0.29 & 0.32 & 0.48 & -0.23 & -0.44 & 1 & & \\
\hline leader11 & 0.42 & 0.27 & 0.36 & 0.40 & 0.34 & 0.47 & 0.57 & -0.37 & -0.3 & 0.71 & 1 & \\
\hline leader12 & 0.35 & 0.15 & 0.23 & 0.34 & 0.24 & 0.37 & 0.45 & -0.34 & -0.45 & 0.63 & 0.49 & 1 \\
\hline
\end{tabular}

Note: Some leadership factors are correlated negatively, and Correlation Matrix between various factors of leadership styles and safety climate has shown in the above table 2. Management by Exception (Passive) and Laissez-Faire behaviours of leadership have a negative correlation to most of the leadership styles factors. In contrast, Contingent Reward and Management by Exception (Active) have a positive correlation to all leadership style's factors. 
Statistical data analysis of this research results is shown in Table 6 below.

Table 6. Mean, standard deviation, minimum and maximum values of leadership style's factors

\begin{tabular}{|c|c|c|c|c|c|}
\hline Variable & Obs & Mean & Std. Dev. & Min & Max \\
\hline safety & 300 & 2.82 & 0.38 & 2.26 & 3.92 \\
\hline safety1 & 300 & 2.83 & 0.56 & 2.00 & 4.00 \\
\hline safety2 & 300 & 2.79 & 0.30 & 2.14 & 3.57 \\
\hline safety3 & 300 & 2.74 & 0.77 & 1.83 & 3.33 \\
\hline safety4 & 300 & 2.96 & 0.36 & 2.33 & 3.66 \\
\hline safety5 & 300 & 2.83 & 0.50 & 2.00 & 4.00 \\
\hline safety6 & 300 & 2.82 & 0.46 & 2.00 & 3.62 \\
\hline safety7 & 300 & 2.77 & 0.30 & 2.14 & 3.57 \\
\hline leader1 & 300 & 2.57 & 0.66 & 0.50 & 4.00 \\
\hline leader2 & 300 & 2.76 & 0.48 & 0.75 & 4.00 \\
\hline leader3 & 300 & 2.69 & 0.51 & 0.75 & 4.00 \\
\hline leader4 & 300 & 2.46 & 0.59 & 0.75 & 4.00 \\
\hline leader5 & 300 & 2.37 & 0.62 & 0.50 & 3.75 \\
\hline leader6 & 300 & 2.03 & 0.59 & 0.25 & 3.50 \\
\hline leader7 & 300 & 1.64 & 0.80 & 0.25 & 4.00 \\
\hline leader8 & 300 & 1.45 & 0.89 & 0.00 & 3.75 \\
\hline leader9 & 300 & 1.33 & 0.59 & 0.25 & 3.50 \\
\hline leader10 & 300 & 1.33 & 0.88 & 0.00 & 3.00 \\
\hline leader11 & 300 & 1.24 & 0.78 & 0.00 & 3.00 \\
\hline & 1.21 & 0.94 & 0.00 & 4.00 \\
\hline
\end{tabular}

Safety climate scores and leadership styles scores in 10 different airlines are tabulated in Table 6. The scores are out of 4 , and a higher number shows a better result. All aviation organizations have the highest score in workers' trust in the safety system, semi-government aviation organizations have the lowest score in management safety justice, and private aviation organizations have the highest score in management safety priority. Overall, safety was better in private aviation organizations in Nepal. Similarly, all aviation organizations have an average safety mean of 2.82 out of 4 , which means no aviation organization in Nepal has a satisfactory safety 
level as per the research findings. Likewise, the mean score of the transformation leadership style is 2.57 , and it is 1.70 for the transactional leadership style, whereas it is only 1.27 for the LaissezFaire leadership style. This indicates that the transformational leadership style has a better safety record than the other two leadership styles. In Table 7 below, four regression analysis results are presented:

Table 7. Regression analysis between safety climate and leadership styles by using STATA

\begin{tabular}{|c|c|c|c|c|c|c|c|}
\hline \multirow[t]{2}{*}{ Source } & \multirow[t]{2}{*}{ SS } & \multicolumn{2}{|l|}{ df } & \multicolumn{2}{|l|}{ MS } & \multirow{2}{*}{$\begin{array}{l}\text { Number of obs } \\
F(12,287)\end{array}$} & \multirow{2}{*}{$\begin{array}{l}300 \\
81.45\end{array}$} \\
\hline & & & & & & & \\
\hline Model & 34.48 & \multicolumn{2}{|c|}{12} & \multicolumn{2}{|l|}{2.870} & Prob $>\mathrm{F}$ & 0 \\
\hline \multirow[t]{2}{*}{ Residual } & \multirow[t]{2}{*}{10.1264} & \multicolumn{2}{|c|}{287} & \multicolumn{2}{|l|}{0.035} & R-squared & 0.77 \\
\hline & & & & & & Adj R-squared & 0.76 \\
\hline Total & 44.61 & \multicolumn{2}{|c|}{299} & \multicolumn{2}{|l|}{0.140} & Root MSE & 0.18 \\
\hline safety & Coef. & Std. Err. & $\mathrm{t}$ & & $P>t$ & [95\% Conf. & Interval] \\
\hline leader1 & 0.03 & .020 & 1.50 & & 0.13 & -0.009 & 0.07 \\
\hline leader2 & 0.01 & .026 & 0.52 & & 0.60 & -0.03 & 0.06 \\
\hline leader3 & 0.02 & .025 & 0.87 & & 0.38 & -0.02 & 0.07 \\
\hline leader4 & 0.01 & .021 & 0.87 & & 0.38 & -0.02 & 0.06 \\
\hline leader5 & 0.03 & .019 & 1.62 & & 0.10 & -0.006 & 0.07 \\
\hline leader6 & 0.06 & .026 & 2.45 & & 0.01 & 0.01 & 0.11 \\
\hline leader7 & 0.04 & .018 & 2.25 & & 0.02 & 0.005 & 0.07 \\
\hline leader8 & -0.12 & .016 & -7.41 & & 0.00 & -0.15 & -0.09 \\
\hline leader9 & -0.17 & .025 & -6.83 & & 0.00 & -0.22 & -0.12 \\
\hline leader10 & -0.004 & .021 & -0.21 & & 0.83 & -0.04 & 0.037 \\
\hline leader11 & 0.13 & .023 & 5.83 & & 0.00 & 0.08 & 0.18 \\
\hline leader12 & 0.03 & .016 & 2.23 & & 0.02 & 0.004 & 0.06 \\
\hline _cons & 2.53 & .12 & 20.94 & & 0.00 & 2.29 & 2.77 \\
\hline
\end{tabular}

This above analysis of the total safety and 12 transformational, transactional and lassiez-faire leadership styles (Non-transactional) factors are correlated utilizing the SPSS software. The Leadership constructs show that the R square value is 0.77 . A T-test of independence resulted in the t-value of almost zero with a corresponding P-value. Since the T-value is higher than the tabulated value and $p$-value is less than 0.05 , my assumption of no relationship between leadership styles cannot be accepted. The relationship between leadership styles and safety 
climate cannot be rejected. It is therefore concluded that there was substantial evidence of the relationship between leadership styles with safety climate. Transformational leaders scored higher in safety climate scores compared to transactional leaders. Moreover, since the R-squared value was $=0.77$, this empirical research can be considered a reliable test and could be viewed as a valid survey in the Nepali airlines industry. As per the author's knowledge, leadership constructs are complicated to measure because these are latent variables.

\section{DISCUSSION}

This research aimed to examine the relationship between leadership style and safety climate in Nepali domestic airlines. To determine the MLQ scores, the scores from the respondents were averaged for each leadership style scale. There is a strong relationship between leadership styles and safety climate in the Nepali aviation organizations. Leadership styles factors are: for Transformational- Idealized Influence (Attributes), Idealized Influence (Behaviors), Inspirational Motivation, Intellectual Stimulation, and Individualized Consideration. For Transactional: Contingent Reward, Management by Exception (Active), and Management by Exception (Passive). For Non-Transactional: Laissez-Faire, Extra Effort, Effectiveness, and Satisfaction. These different 12 factors are correlated with each other, as shown in Table 5. These are mostly positively correlated with each other for safety improvement.

Likewise, Table 8 shows how different dimensions of safety climate correlate. Safety dimensions are management safety priority and ability, management safety empowerment, management safety justice, workers' safety commitment, workers safety priority, and risk non-acceptance, safety communication, learning, and trust in safety ability and workers' trust in the efficacy of safety systems scores are better in private aviation organizations.

All safety dimensions have positive correlations. Research findings also indicate that the leadership style used in these three types of aviation organizations in Nepal has three different safety climate scores. It was found that transformational leadership has a higher safety climate score of 2.8 in private aviation organizations, which in turn scored 24.38 points in safety climate. Similarly, the government organization scored 18.72, and the semi-government aviation organization scored only 17.49 , which was less compared to the other two leadership styles. No Nepali airlines organization achieved a high safety score level, as per the requirements. To 
determine if the leadership styles are associated with the safety climate score, the scoring was grouped into three ranges: 15 to 19 - Low Safety, 20 to 24 - Medium Safety, 25 to 28 - High Safety. It was found that the government organization has a slightly better safety climate than the semi-government aviation organization. Likewise, the transformational leadership style is better for achieving the highest safety climate score than transactional leadership. However, the laissez-faire leadership style is not perceptible in all three aviation organizations in Nepal. Table 9 indicates the safety climate scores of these three types of aviation organizations in Nepal.

Table 8. Correlation Matrix between Safety Climates Dimensions

\begin{tabular}{|c|c|c|c|c|c|c|c|c|}
\hline Variables & $\begin{array}{c}\text { Total } \\
\text { safety }\end{array}$ & safety1 & safety2 & safety3 & safety4 & safety5 & safety6 & safety7 \\
\hline Total safety & 1 & & & & & & & \\
\hline safety1 & 0.91 & 1 & & & & & & \\
\hline safety2 & 0.84 & 0.73 & 1 & & & & & \\
\hline safety3 & 0.70 & 0.56 & 0.47 & 1 & & & & \\
\hline safety4 & 0.88 & 0.79 & 0.79 & 0.47 & 1 & & & \\
\hline safety5 & 0.94 & 0.85 & 0.80 & 0.54 & 0.83 & 1 & & \\
\hline safety6 & 0.69 & 0.63 & 0.58 & 0.10 & 0.67 & 0.73 & 1 & 1 \\
\hline safety7 & 0.85 & 0.74 & 0.73 & 0.51 & 0.77 & 0.79 & 0.57 & 1 \\
\hline
\end{tabular}

Table 9. Safety Climate Score Results

\begin{tabular}{|c|c|c|c|c|}
\hline S. No. & Type of Aviation Organization & Safety Climate Score & Results & Remarks \\
\hline 1 & Government-owned Airlines & 18.72 & $\begin{array}{c}15 \text { to } 19 \\
\text { Low Safety }\end{array}$ & Low safety climate \\
\hline 2. & Semi-Government owned Airlines & 17.49 & $\begin{array}{c}15 \text { to } 19 \\
\text { Low Safety }\end{array}$ & $\begin{array}{l}\text { Low safety climate, less } \\
\text { than both government } \\
\text { as well as private } \\
\text { airlines of Nepal }\end{array}$ \\
\hline 3. & Private Airlines & 24.38 & $\begin{array}{c}20 \text { to } 24 \\
\text { Medium } \\
\text { Safety, } 25 \text { to } \\
28 \text { High } \\
\text { Safety }\end{array}$ & $\begin{array}{l}\text { Higher safety climate } \\
\text { than both government } \\
\text { as well as semi- } \\
\text { government airlines }\end{array}$ \\
\hline
\end{tabular}


From the table above, the scores indicate that a high score for management safety justice followed by workers safety commitment, peer safety communication learning and trust in safety ability, workers safety priority and risk non-acceptance, management safety empowerment, and workers trust in safety systems. The scores show that the semigovernment organization has the lowest scores in all safety climate dimensions compared to the government and private organizations. The private organizations were among the best in safety scores, but they have not reached high safety scores, which is usually desirable for aviation safety. Therefore, the author would like to emphasize safety-related management practices in the aviation industries. Some interpretations of the empirical result findings of research on leadership styles and aviation safety climate are summarized as follows:

- The lower the correlation between the independent variables, the better the model. Mostly the correlations of all independent variables are low value.

- Out of twelve, eight-construct variables are significant at $5 \%$ level. Therefore, it is one of the reliable empirical research findings.

- Increase in Leader 8, 9, and 10 construct variables, which means Management by Exception (Passive) Non-Transactional Leadership Styles, Laissez-Faire, Extra Effort factors of leadership styles decreases the safety level.

- Transformational leadership style constructs have more responses than others do.

- Managers are better than staff concerning aviation safety; Managers are more serious in safety-related issues.

- Compared to managers, the response of safety decreases 0.06 in the case of staff.

- The females are safer than the male by 0.01 (refer to Table 10).

- Institutions type as such do not affect safety, but the private organizations in Nepal look better than the other two types of organization.

- A few construct variables are negatively correlated. They are Management by Exception (Passive) and Laissez-Faire. Hence, it is better not to practise such behaviours or adopt such leadership styles in aviation organizations.

The above research findings indicate that leadership style is highly correlated with aviation safety and transformational styles have better safety levels. All safety dimensions have some effects on the total aviation safety. Some have positive effects, and some have negative effects. Transformational leadership constructs have positive eigenvectors whereas transactional leadership style constructs (Leader 8), i.e., Management by Exception (Passive) and non-transactional leadership style construct (Leader 9) Laissez-Faire, Extra Effort factors of leadership styles have negative effects on the overall safety climate of the aviation industry. 
Table 10 below correlated all factors along with the institution, sex, and status of the respondents. In particular, Working staff compared to managers have -0.06 less safety level. Likewise, female workers have 0.01 more safety than male workers. All transformational leadership styles constructs have positive and higher value of coefficients compared to other leadership constructs. Eight constructs variables are significant at 5\% level, and almost all are significant within the $10 \%$ level, as shown in Table 10. In this status, institute and gender are taken for regression analysis.

Table 10. Regression analysis between safety climate and leadership styles including institute, gender and status.

\begin{tabular}{|c|c|c|c|c|c|c|}
\hline \multirow[t]{2}{*}{ Source } & \multirow[t]{2}{*}{ SS } & \multirow[t]{2}{*}{ df } & \multicolumn{2}{|l|}{ MS } & \multirow{2}{*}{ Number of obs } & \multirow{2}{*}{$\begin{array}{c}300 \\
63.38\end{array}$} \\
\hline & & & & & & \\
\hline Model & 34.87 & 16 & 2.17 & & Prob $>\mathrm{F}$ & 0 \\
\hline \multirow[t]{2}{*}{ Residual } & 9.73 & 283 & 0.03 & & R-squared & 0.78 \\
\hline & & & & & Adj R-squared & 0.76 \\
\hline Total & 44.61 & 299 & 0.14 & & Root MSE & 0.18 \\
\hline safety & Coef. & \multicolumn{2}{|c|}{ Std. Err. $\mathrm{t}$} & $P>t$ & [95\% Conf. & Interval] \\
\hline Working Staff & -0.06 & .024 & -2.58 & 0.01 & -0.11 & -0.01 \\
\hline Manager & 0.04 & .033 & 1.27 & 0.20 & -0.02 & 0.10 \\
\hline Female & 0.01 & .023 & 0.47 & 0.64 & -0.03 & 0.05 \\
\hline Male & -0.02 & .029 & -0.93 & 0.35 & -0.08 & 0.03 \\
\hline leader1 & 0.02 & .020 & 1.23 & 0.22 & -0.01 & 0.06 \\
\hline leader2 & 0.00 & .026 & 0.37 & 0.71 & -0.04 & 0.06 \\
\hline leader3 & 0.02 & .024 & 1.02 & 0.31 & -0.02 & 0.07 \\
\hline leader4 & 0.02 & .021 & 1.32 & 0.18 & -0.01 & 0.07 \\
\hline leader5 & 0.03 & .019 & 1.84 & 0.06 & -0.002 & 0.07 \\
\hline leader6 & 0.05 & .026 & 2.22 & 0.02 & 0.006 & 0.11 \\
\hline leader7 & 0.04 & .018 & 2.23 & 0.02 & 0.004 & 0.07 \\
\hline leader8 & -0.11 & .016 & -6.85 & 0.00 & -0.14 & -0.08 \\
\hline leader9 & -0.17 & .027 & -6.33 & 0.00 & -0.22 & -0.11 \\
\hline leader10 & 0.00 & .021 & 0.36 & 0.72 & -0.03 & 0.05 \\
\hline leader11 & 0.12 & .023 & 5.55 & 0.00 & 0.08 & 0.17 \\
\hline leader12 & 0.03 & .016 & 2.20 & 0.02 & 0.003 & 0.06 \\
\hline _cons & 2.53 & .12 & 20.30 & 0.00 & 2.29 & 2.78 \\
\hline
\end{tabular}

These research findings of aviation organizations have different characteristics than the research findings of general organizations, which the author has discussed in the literature review section. The nuclear processing plant safety climate research findings suggested that leadership behaviours are crucial for safety climate (Lee, 1998). Lee did not highlight which 
particular factors of leadership had vital effects on aviation safety. His findings emphasized the requirement of an autocratic leadership style in the nuclear plant since it belongs mostly to military organizations. He also highlighted the need of safety information to improve the safety climate of the organization. Likewise, another research in the field has been carried out in road transportation administration, which found that leaders, rather than any other employees, can build the workplace's safety culture (Niskanen, 1994). It is valid to some extent in the case of the aviation organization as well. However, as per Niskanen's research, the role of subordinates had not been brought forward clearly. The roles of both the leader and the subordinates are included in the single empirical research that the author carried out in Nepal's aviation industry. In this, both top managers and working-class employees have participated in the survey. All factors of individual leadership roles in the overall safety score as well as correlation matrix have been tabulated in the result section, which was not in the case of these two general organizations (namely, nuclear plant and road transport). It can also be concluded that different organizations like aviation, nuclear, transport etc. have their own unique safety climate. Hence, we cannot generalize the research findings of aviation organizations to other such general organizations.

The research finding has given priority for transformational leadership style for better safety performance. Although all safety, as well as leadership styles, construct variables are very difficult to measure, the above result findings, especially, values of Cronbach alpha, can be taken as satisfactory for such complex research which has seven dependent constructs variables of safety and twelve independent construct variables (Refer Table 2 and Table 3).

\section{THEORETICAL AND EMPIRICAL CONTRIBUTION}

The overall goal of this research is to identify the relationship between leadership styles and safety climate in the Nepali airlines industry. This research has concluded some crucial findings on safety climate scores in all three types of aviation organizations in Nepal. All three types of organizations could not reach the highest score of safety climate. However, private aviation organizations are better than government and semi-government aviation organizations in Nepal. It has clearly indicated that transformational leadership is the best for the aviation industry. Out of five transformational leadership factors, intellectual stimulation and individualized consideration can contribute to higher aviation safety than any other factors of transformational leadership. Therefore, all aviation leaders can prefer these two factors of 
transformational leadership to improve the safety level. This is a significant finding of this empirical research, which could be valuable knowledge in leadership, especially in the aviation sector.

This study implies that it is more desirable to have aviation leaders who practice transformational leadership style, which may encourage a safe climate for workers. Workers' trust in the safety system was higher in government and semi-government organizations than in private organizations. Still, the rest of all values were better in private airlines, which indicates that the safety climate is better in private aviation organizations in Nepal. The data show that management's safety priority and commitment were the highest in private airlines and government organization comes in the second position. A semi-Government organization comes at last in terms of the safety score.

This research article is the very first article which studied aviation leadership safety styles and safety climate. It is also the very first of such nature, as per the author's knowledge, and will have a high impact on academic and aviation management to improve aviation safety, which in turn gives the higher financial and economic value of the aviation organization. Therefore, the author hopes this research will add some knowledge in aviation leadership's styles, which can affect aviation safety climate. Besides, the readers will understand which leadership style will be the best for higher safety climate. It can help reduce the air accident rate worldwide, saving several lives and a considerable amount of money. As a research scholar, the author hopes this article will also help further research in aviation safety.

\section{LIMITATIONS OF THE RESEARCH}

The research findings of this study are subject to several confines. First, this study's samples are limited to the personnel of ten airline organizations based in Kathmandu, Nepal. The sample size was relatively small $(n=300)$. Therefore, a generalization of the findings might be limited. Larger sample size may provide more validated results on the same study. Likewise, the subordinates were not always tied to a single leader, and thus, the interference of other leaders with different leadership styles could affect the responses of the respondents and may not precisely reflect the right safety climate under the targeted leader. Another limitation of the current study relates to the characteristics or demographics of the sample. The sample was gender-biased with a female size of less than $33 \%$. This reflects the trend in typical Nepali aviation organizations in Nepal but may not reflect the trend in other countries. Since different 
organizations like aviation, nuclear, transport, etc., have their unique safety climate, we cannot generalize aviation organizations' research findings to other such general organizations.

The author would like to suggest that further research will be needed on whether there will be any relationship between leadership and individual safety constructs. Hence, future research in the same field, considering all these issues, is recommended. Such safety constructs and leadership styles constructs are sometimes difficult to measure by the quantitative method, and the result's interpretation will be difficult. Therefore, a mixedmethods approach can shed more light on aviation safety research.

\section{SUMMARY AND CONCLUSIONS}

This research concluded that aviation safety is highly correlated with leadership. Out of three leadership styles, the transformational leadership style has a greater safety climate score than the other two (i.e., transactional and laissez-faire) leadership styles. Within these types of leadership styles, their different factors have different influence on that particular style of leadership. Some factors of leadership styles have a negative influence on aviation safety. Increase in Leader 8, 9, and 10 construct variables that means Management by Excerption (Passive) Non-Transactional Leadership Styles, Laissez-Faire, and Extra Effort factors of leadership styles decrease the safety level. Moreover, the transformational leadership style constructs have more responses than others do. Aviation managers are better than staff concerning aviation safety; managers are more serious in safety-related issues. Compared to the managers, the response of safety decreases 0.06 in the case of staff. Furthermore, the female staff is safer than the male by 0.01 . Institutions do not affect safety, but the private organizations in Nepal look better than the other two types of organizations. The research findings clearly show that transformational leadership has a higher safety score than any different leadership styles. Therefore, to achieve more aviation safety, the transformational leadership style needs to be fostered. Aviation leaders can adopt this style to reduce air accidents or incidents in the airlines. This research also identified a few core competencies of the aviation leaders within the transformational leadership style, including Intellectual stimulation and individualized consideration, which can contribute to higher aviation safety than any other transformational leadership factors.

\section{REFERENCES}

- ACSNI. (1993). Organizing for safety. Advisory Committee on the Safety of Nuclear Installations, Human Factors Study Group, third report. HSE Books. 
- Alam, M. A. (2015). Techno-stress and productivity: Survey evidence from the aviation. Journal analytic test of the relative validity. Journal of Applied Phsycology. 1030-1020.

- Andoh, M. (2013). The relationship between leadership style and safety.

- Avolio, B. J., Bass, B. M., \& Jung, D. I. (1995). MLQ multifactor leadership questionnaire: Technical report. Mindgarden.

- Barrick, M., \& Mount, M. (1991). The 'big 5' personality dimensions and job performance: A meta-analysis. Personnel Psychology, 44, 1-25

- Bass, B. M. (1985). Leadership and performance beyond expectations. Free Press.

- Bass, B. M., \& Avolio, B. J., E. (1997). The full range of leadership development: Manual for the multi-factor leadership questionnaire. Mindgarden.

- Bastola, D. P. (2017). Organizational analysis of the aviation industry from the performance-based perspective. International Journal of Commerce and Management Research, 3 (10), 24-32.

- Civil Aviation Authority of Nepal. (2020). CAAN report. https://www.caanepal.org.np/en/

- Chena, C. F. (2013). Proceedings of the Eastern Asia Society for Transportation Studies, 9 - Constructive developmental analysis. Academy of Management Review, 12(4), 657-648.

- Cox, S., \& Cox, T. (1991). The structure of employee attitudes to safety: A European example. Work \& Stress, 5, 93-106.

- Diaz, R., \& Cabrera, D. (1996). Safety climate and attitude as evaluation measures of organizational safety. Accident Analysis and Prevention, 29(5), 643-650.

- Flin, R. (1998). Safety condition monitoring. Lessons from 'man-made disasters'. Journal of Contingencies and Crisis Management, 6, 88-92.

- Fuller, C. W. (1999). An employee-management consensus approach to continuous improvement in safety management. Employee Relations, 21, 405-417.

- Hofmann, D. A., \& Stetzer, A. (1996). A cross-level investigation of factors influencing unsafe behaviors and accidents. Personnel Psychology, 49, 307-339.

- International Civil Aviation Organization. (2020). ICAO report. https://www.icao.int/safety/Pages/Safety-Report.aspx

- Kelly, T., Lercel, D., \& Patankar, M. (2015). Influence of trust and job satisfaction on safety climate among managers at a large U.S. air carrier. Management and Organizational Studies, 2(2), 57-67. https://doi.org/10.5430/mos.v2n2p57

- Kelly, T. M. (2012). Safety culture: Testing the safety culture pyramid with structural equation modeling. Center for Aviation Safety Research.

- Kines, P., Lappalainen, J., Mikkelsen, K. L., Puosette, A., Tharaldsen, J., \& Tòrnmasson, K. (2011). Nordic safety climate questionnaire (NOSACQ - 50): A new tool for measuring 
occupational safety climate. International Journal of Industrial Ergonomics, 41(6), 646634.

- Lee, T. (1998). Assessment of safety culture at a nuclear reprocessing plant. Work and Stress, 12(3), 217-237.

- Niskanen, T. (1994). Safety climate in the road administration. Safety Science, 17(4), 237255.

- O'Connor, P. (2011). Measuring safety climate in the aviation industry, $A$ review of air transport management.

- Patankar, M. S., \& Sabin, E. J. (2010). The safety culture perspective. In Human factors in aviation (pp. 95-122). https://doi.org/10.1016/b978-0-12-374518-7.00004-3

- Reason, J., Parker, D., \& Lawton, R. (1998). Organizational controls and safety: The varieties of rule-related behavior. Journal of Occupational and Organizational Psychology, 71, 289-304.

- Simard, M., \& Marchand, A. (1994). The behavior of first line supervisors in accident prevention and effectiveness in occupational safety. Safety Science, 17, 169-185.

- Smith, M., Cohen, H., Cohen, A., \& Cleveland, R. (1978). Characteristics of successful safety programs. Journal of Safety Research, 10(1), 5-15.

- Wameedh, A. K., Faridahwati, M. S., \& Subramanim, C. (2011). Improving safety performance by understanding relationship between management practices and leadership behaviour in the Oil and Gas industry in Iraq: A proposed model. Proceedings of the International Conference on Management and Artificial Intelligence, 6, 85-93.

- Williamson, A. M., Feyer, A., Cairns, D., \& Biancotti, D. (1997). The development of a measure of safety climate: The role of safety perceptions and attitudes. Safety Science, 25(1-3), 15-27.

- Yang, C., Wang, Y., Chang, S., Guo, S., \& Huang, M. (2010). A Study on the leadership behavior, safety culture, and safety performance of the healthcare industry. Educational and Psychological Sciences, 2, 94-87.

- Yukl, G. A. (2010). Managerial leadership: A review of theory and research (7 $7^{\text {th }}$ ed.). Person Education

\section{AUTHOR'S BIO}

Dipak Prasad Bastola is an Aeronautical Engineer in Nepal who had studied in India for his B.E. in Aeronautical Engineering from HIET, Hindustan Group of Institutions, Chennai. He has earned a Master's degree in Aerospace Management from Toulouse Business School, Toulouse, 
France and he is currently pursuing a PhD in Management at Kathmandu University School of Management, Lalitpur, Nepal. The author has vast experience in management and aviation fields in the Nepalese Government and civil sector. He is one of the very experienced aviation experts who have a sound academic background in aircraft maintenance. Email: 141001 dipak@kusom.edu.np 